Pacific Journal of Mathematics

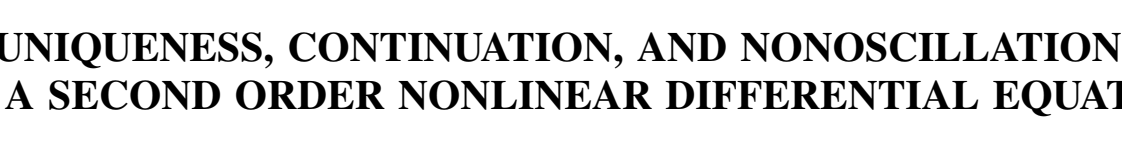




\title{
UNIQUENESS, CONTINUATION, AND NONOSCILLATION FOR A SECOND ORDER NONLINEAR DIFFERENTIAL EQUATION
}

\author{
J. W. HEIDEL
}

This paper considers the differential equation (1) $y^{\prime \prime}+$ $f(t) y^{\gamma}=0$ where $f(t)$ is nonnegative and continuous on $[0, \infty)$ and $\gamma$ is the quotient of odd, positive integers. For this equation we discuss uniqueness of the zero solution, continuation of solutions to $[0, \infty)$, and nonoscillation of solutions. Using a relation between uniqueness and continuation on the one hand and nonoscillation on the other, we can show that the condition $f^{\prime}(t) \leqq 0$ in Atkinson's nonoscillation theorem (Pacific J. Math. 5 (1955), 643-647), and in a corresponding theorem for $0<\gamma<1$, cannot be removed entirely.

The equation to be considered is

$$
y^{\prime \prime}+f(t) y^{r}=0
$$

where $f(t)$ is nonnegative and continuous on $[0, \infty)$ and $\gamma=p / q$ where $p$ and $q$ are odd positive integers. These assumptions will hold throughout this paper. We will be concerned only with real valued solutions. Coffman and Ullrich [2] have shown that if, in addition, $f(t)$ is positive and locally of bounded variation on $[0, \infty)$ and $\gamma>1$, then all solutions can be continued to $[0, \infty)$. Our purpose here is threefold. First we give a result involving uniqueness of the zero solution of (1) which is analogous to Coffman and Ullrich's, but for the case $0<\gamma<1$. Secondly we extend these two results to allow $f(t)$ to have isolated zeros. Finally, we give a connection between either continuation or uniqueness on the one hand and the nonoscillation problem for (1).

We begin with some definitions and basic facts. The assumption on $\gamma$ yields that solutions of (1) with real valued initial conditions are real valued and the negative of a solution of (1) is again a solution.

LEMma 1. If $0<\gamma<1$, all solutions of (1) can be continued to $[0, \infty)$. If $1<\gamma$, then there is a unique solution satisfying any set of initial conditions.

Continuation follows from a theorem of Wintner (Hartman [4, p. 29]). Uniqueness follows from the local Lipschitz condition. Here we will be concerned with continuation for $1<\gamma$ and its analogue for $0<\gamma<1$ which is uniqueness of the zero solution (trivial solution). By definition we say that the zero solution is unique if any solution $y(t)$ of (1) 
satisfying the initial conditions $y\left(t_{0}\right)=y^{\prime}\left(t_{0}\right)=0$ for some $t_{0} \geqq 0$ will then necessarily satisfy $y(t)=0$ for all $t \geqq 0$. A nontrivial solution of (1) which has zero initial conditions at some point will be called singular, following Kiguradze [6].

Lemma 2. Suppose $0<\gamma<1$. A nontrivial solution $y(t)$ of $(1)$ is singular if and only if $y(t)$ has an infinite number of zeros on a finite interval.

Proof. Suppose $y(t)$ is singular, $y^{2}\left(t_{0}\right)+y^{\prime 2}\left(t_{0}\right)>0, y^{2}\left(t_{1}\right)+y^{\prime 2}\left(t_{1}\right)=$ 0 , and $t_{0}<t_{1}$. Suppose that $y(t)$ has no zero on $\left(t_{0}, t_{1}\right)$, and that $y(t)>$ 0 on $\left(t_{0}, t_{1}\right)$. Then $y^{\prime}(t)$ is decreasing on $\left(t_{0}, t_{1}\right)$ and therefore contradicts $y^{\prime}\left(t_{1}\right)=0$. If $y(t)$ has a last zero before $t_{1}$, at $t_{2}$, then the same argument holds on $\left(t_{2}, t_{1}\right)$. Therefore $y(t)$ does not have a last zero on $\left(t_{0}, t_{1}\right)$, that is, $y(t)$ has an infinity of zeros on $\left(t_{0}, t_{1}\right)$, clustering at $t_{1}$. A similar argument applies if $t_{1}<t_{0}$.

Conversely, suppose that $y(t)$ has an infinity of zeros on some finite interval $\left(t_{0}, t_{1}\right)$. Then they cluster at some $t^{*}, t_{0} \leqq t^{*} \leqq t_{1}$; by continuity $y\left(t^{*}\right)=0$, and by the mean value theorem and continuity $y^{\prime}\left(t^{*}\right)=0$.

2. In this section we consider uniqueness of zero solution when $0<\gamma<1$. The techniques are modified from Coffman and Ullrich [2].

THEOREM 1. Suppose that $0<\gamma<1$ and that $f(t)$ is positive and class $C^{\prime}$ on $[0, \infty)$. Then the zero solution of (1) is unique.

Proof. Suppose that $y(t)$ is a solution of (1) such that $\left(y\left(t_{0}\right)\right)^{2}+$ $\left(y^{\prime}\left(t_{0}\right)\right)^{2}>0$ for some $t_{0} \geqq 0$. It suffices to show that $(y(t))^{2}+\left(y^{\prime}(t)\right)^{2}>0$ for all $t \geqq 0$. Let $t_{1}>t_{0}$. Let

$$
\Phi(t)=\frac{2 f(t)}{\gamma+1}(y(t))^{\gamma+1}+\left(y^{\prime}(t)\right)^{2} .
$$

Then $\Phi^{\prime}(t)=(2 /(\gamma+1)) f^{\prime}(t)(y(t))^{\gamma+1}$. Therefore

$$
\Phi^{\prime}(t) \geqq-\frac{2}{\gamma+1} \frac{\left|f^{\prime}(t)\right|}{f(t)} \Phi(t) .
$$

An integration shows that

$$
\Phi(t) \geqq \Phi\left(t_{0}\right) \exp \left(-\int_{t_{0}}^{t_{1}} g(s) d s\right), t_{0} \leqq t \leqq t_{1}
$$

where $g(t)=(2 /(\gamma+1))\left(\left|f^{\prime}(t)\right| / f(t)\right)$. Since 


$$
\int_{t_{0}}^{t_{1}}\left(\left|f^{\prime}(x)\right| / f(s)\right) d s<\infty
$$

it follows that $\Phi(t)>0$ for $t_{0} \leqq t \leqq t_{1}$. Therefore $(y(t))^{2}+\left(y^{\prime}(t)\right)^{2}>0$ for $t_{0} \leqq t \leqq t_{1}$. Since $t_{1}$ is arbitrary, $(y(t))^{2}+\left(y^{\prime}(t)\right)^{2}>0$ for $t_{0} \leqq t$. A similar argument applies for $t_{1}<t_{0}$.

REMARK. In their continuation theorem Coffman and Ullrich were able to replace class $C^{\prime}$ by locally of bounded variation. Their approximation argument breaks down in our case because we are dealing with uniqueness rather than continuation.

EXAMPLE 1. The example given by Coffman and Ullrich of an equation (1) with a noncontinuable solution can be modified to give an example where the zero solution is not unique, when $0<\gamma<1$. Since this example will be used later in this paper, we will outline its construction. The following lemma is a simple modification of a lemma of Coffman and Ullrich [2].

Lemma 3. Suppose $0<\gamma<1$. For each positive integer $n$, there exists a continuous function $q_{n}(t)$ on $[0,1]$ with $q_{n}(0)=q_{n}(1)=0$ and such that

$$
\frac{d^{2} U}{d t^{2}}+\left(C^{2}+q_{n}(t)\right) U^{r}=0
$$

where $C$ is a suitable constant, has a solution $U_{n}(t)$ satisfying

$$
\frac{d U_{n}(0)}{d t}=\frac{d U_{n}(1)}{d t}=0, U_{n}(0)=1, U_{n}(1)=\left(\frac{n}{n+1}\right)^{4 /(1-r)}
$$

and having at least two zeros in $(0,1)$. In addition the $q_{n}(t)$ can be chosen in such a way that each is of bounded variation in $[0,1]$ with

$$
\int_{0}^{1}\left|d q_{n}(t)\right| d t \leqq k\left(\frac{1}{n}\right)
$$

for a suitable $k$.

Construction of example. Define

$$
\sigma_{1}=0, \sigma_{n}=\sum_{k=1}^{n-1} \frac{1}{k^{2}}, n>1 .
$$

Note that $\lim _{n \rightarrow \infty} \sigma_{n}=\pi^{2} / 6$. Now $f(t)$ and $y(t)$ (which will be the solution of (1)) are defined on $\left[0, \pi^{2} / 6\right)$ as follows,

$$
\begin{aligned}
& f(t)=C^{2}+q_{n}\left(n^{2}\left(t-\sigma_{n}\right)\right) \sigma_{n} \leqq t \leqq \sigma_{n+1} \\
& y(t)=\left(1 / n^{4 / 1-r}\right) U_{n}\left(n^{2}\left(t-\sigma_{n}\right)\right) \sigma_{n} \leqq t \leqq \sigma_{n+1} .
\end{aligned}
$$


Define $f(t)=C^{2}$ for $t \geqq \pi^{2} / 6$. Then, as in Coffman and Ullrich [2], it follows readily that $f(t)$ is positive and continuous on $[0, \infty)$ and that $y(t)$ is a solution of $(1)$ on $\left[0, \pi^{2} / 6\right)$. Continue $y(t)$ to $[0, \infty)$ by Lemma 1. Since $y\left(\sigma_{n}\right)=\left(1 / n^{4 / 1-\gamma}\right)$ it follows that $y\left(\pi^{2} / 6\right)=y^{\prime}\left(\pi^{2} / 6\right)=0$.

3. In this section we will show that $f(t)$ can have isolated zeros and continuation and uniqueness will still hold. First of all we state two nonoscillation theorems which will be needed.

Theorem A ([1]). Suppose that $1<\gamma$ and that $f(t)>0, f^{\prime}(t) \leqq 0$, $0 \leqq t<\infty$. If

$$
\int^{\infty} s^{\gamma} q(s) d s<\infty
$$

then all nontrivial solutions of (1) are nonoscillatory (i.e., have a finite number of zeros on $[0, \infty)$.

THEOREM B ([5]). Suppose that $0<\gamma<1$ and that $f(t)>0$, $f^{\prime}(t) \leqq 0,0 \leqq t<\infty$. If

$$
\int^{\infty} s q(s) d s<\infty
$$

then all nontrivial solutions of (1) are nonoscillatory.

Theorem 2. Let $\gamma>1$. Suppose that on the interval $[0, \infty) f(t)$ is continuous, locally of bounded variation, and positive except at a sequence of isolated points $\left\{t_{i}\right\}, i=1,2,3, \ldots$ If $f(t)$ is differentiable in a left neighborhood $\left(t_{i}-\varepsilon, t_{i}\right)$ of each $t_{i}(\varepsilon$ depends on $i)$ and if for each $i$ the function

$$
A(x)=\frac{f\left(t_{i}-\frac{1}{x}\right)}{x^{\gamma+3}}
$$

satisfies $A^{\prime}(x) \leqq 0$ for large $x$, then any solution of (1) existing at some $t_{0} \geqq 0$ can be continued to $\left[t_{0}, \infty\right)$. Likewise if $f(t)$ is differentiable in a right neighborhood $\left(t_{i}, t_{i}+\varepsilon\right)$ of each $t_{i}(\varepsilon$ depends on $i)$ and if for each $i$ the function

$$
A(x)=\frac{f\left(t_{i}+\frac{1}{x}\right)}{x^{\gamma+3}}
$$

satisfies $A^{\prime}(x) \leqq 0$ for large $x$, then any solution of (1) existing at some $t_{0} \geqq 0$ can be continued to $\left[0, t_{0}\right]$. 
Proof. Suppose that $y_{1}(t)$ is defined at $t_{0}$. Then by Coffman and Ullrich's theorem $y_{1}(t)$ exists on $\left[t_{0}, t_{i}\right)$ where $t_{i}$ is the first zero of $f(t)$ to the right of $t_{0}$. Suppose $y_{1}(t)$ can't be continued to $t_{i}$. Then $y_{1}(t)$ has an infinite number of zeros on $\left[t_{0}, t_{i}\right)$ clustering at $t_{i}$. Let

$$
x=\frac{1}{t_{i}-t} \quad y(t)=\frac{w(x)}{x} .
$$

Then (1) is transformed into

$$
w^{\prime \prime}+A(x) w^{\gamma}=0
$$

where

$$
A(x)=\frac{f\left(t_{i}-\frac{1}{x}\right)}{x^{\gamma+3}} .
$$

$y_{1}(t)$ is transformed into a solution $w_{1}(x)$ of $(3) . w_{1}(x)$ exists on $\left[1 /\left(t_{i}-t_{0}\right), \infty\right)$ and is oscillatory (i.e., has arbitrarily large zeros). Also $A(x)$ satisfies

$$
\int^{\infty} s^{\gamma+2-\varepsilon} A(s) d s<\infty
$$

for any $\varepsilon>0$. Since $A^{\prime}(x) \leqq 0$, Theorem $\mathrm{A}$ above says that $w_{1}(x)$ is nonoscillatory. This contradiction shows that $y_{1}(t)$ can be continued to $t_{i}$. Therefore, by standard existence theorem, $y_{1}(t)$ can be continued to a neighborhood of $t_{i}$. By Coffman and Ullrich's theorem $y_{1}(t)$ can be continued up to the next zero of $f(t)$. Since the zeros of $f(t)$ are isolated $y_{1}(t)$ can be continued to $\left[t_{0}, \infty\right)$.

The second part of the theorem follows in a similar manner by making the transformation

$$
x=\frac{1}{t-t_{i}}, \quad y(t)=\frac{w(x)}{x} .
$$

REMARK. The transformation in the preceding theorem has been used previously by Kiguradze [7].

REMARK. Kiguradze [7] has shown that if $f(t)<0$ on some interval $\left(t_{1}, t_{2}\right)$ then (1), with $\gamma>1$, has a solution which can't be continued to the right of $t_{2}$. Therefore a necessary condition for continuation of all solutions is $f(t) \geqq 0$. Whether or not $f(t) \geqq 0$ is sufficient (together with locally of bounded variation) is an open question.

Theorem 3. Let $0<\gamma<1$. Suppose that $f(t)$ is class $C^{\prime}$ on $[0, \infty)$ and positive except for a sequence of isolated points $\left\{t_{i}\right\}, i=$ 
$1,2,3, \cdots$. Suppose that for each $i$ the function

$$
A(x)=\frac{f\left(t_{i}-\frac{1}{x}\right)}{|x|^{r+3}}
$$

satisfies $A^{\prime}(x) \leqq 0$ for large $|x|$. Then the zero solution is unique on $[0, \infty)$.

Proof. Suppose there is a singular solution $y_{1}(t)$. Then $y_{1}(t)$ has an infinite number of zeros clustering at some point $t^{*}$. By Theorem $1, t^{*}=t_{i}$ for some $i$. If the zeros of $y_{1}(t)$ cluster at $t_{i}$ from the left (i.e., on $\left(t_{i}-\varepsilon, t_{i}\right)$ use the first transformation in the proof of Theorem 2. If the zeros of $y_{1}(t)$ cluster at $t_{i}$ from the right use the second transformation in the proof of Theorem 2. Thus $y_{1}(t)$ is transformed into an oscillatory solution $w_{1}(x)$ of

$$
w^{\prime \prime}+A(x) w^{r}=0 \text {. }
$$

Since $A^{\prime}(x) \leqq 0$, this is a contradiction to Theorem B above.

REMARK. By using theorems of Gollwitzer [3], Theorems 2 and 3 can be improved somewhat in the sense that the condition $A^{\prime}(x) \leqq 0$ can be slightly relaxed.

4. Finally, we will answer a conjecture made in [5] about Theorem B and a similar question for Theorem A. The question is, can the condition $f(t)>0, f^{\prime}(t) \leqq 0$ in Theorems $\mathrm{A}$ and $\mathrm{B}$ be replaced by the weaker condition $f(t) \geqq 0$. The answer is no in both cases.

EXAMPle 2. Coffman and Ullrich have shown that there is a continuous function $f(t)>0$ defined on $[0, \infty)$ and a solution $\phi(t)$ of (1) such that $\phi(t)$ exists only on a finite interval $\left[t_{0}, t_{1}\right)$ and has an infinity of zeros clustering at $t_{1}$. Using the transformation of the preceding section $\phi(t)$ is transformed into a solution $w(t)$ of

$$
w^{\prime \prime}+A(x) w^{r}=0
$$

where

$$
A(x)=\frac{f\left(t_{1}-\frac{1}{x}\right)}{x^{\gamma+3}}, \quad x \geqq \frac{1}{\left(t_{1}-t_{0}\right)}
$$

and $w(x)$ is oscillatory on $\left[1 /\left(t_{1}-t_{0}\right), \infty\right)$. Also

$$
\int^{\infty} x^{r} A(x) d x<\infty \text {. }
$$


This shows that the condition $f^{\prime}(t) \leqq 0$ can't be removed in Theorem A.

ExAmPle 3. Similarly, by Example 1 above, let $f(t)$ be a positive and continuous function on $[0, \infty)$ and $\psi(t)$ a solution of (1) for $0<$ $\gamma<1$ such that $\psi(t)$ is singular, $\psi\left(t_{1}\right)=\psi^{\prime}\left(t_{1}\right)=0$, and $\psi(t)$ has an infinity of zeros on some interval $\left[t_{0}, t_{1}\right)$ clustering at $t_{1}$. Then $\psi(t)$ is transformed by the above transformation to $w(x)$ which is a solution of

$$
w^{\prime \prime}+A(x) w^{\gamma}=0, x \geqq 1 /\left(t_{1}-t_{0}\right)
$$

and $w(x)$ is oscillatory on $\left[1 /\left(t_{1}-t_{0}\right), \infty\right)$. Since

$$
\int^{\infty} x A(x) d x<\infty
$$

it is clear that $f^{\prime}(t) \leqq 0$ can't be removed from Theorem B.

REMARK. Again, results of Gollwitzer [3] show that the condition $f^{\prime}(t) \leqq 0$ can be weakened slightly.

\section{REFERENCES}

1. F. V. Atkinson, On second-order non-linear oscillations, Pacific J. Math. 5 (1955), 643-647.

2. C. V. Coffman and D. F. Ullrich, On the continuation of solutions of a certain non-linear differential equation, Monatsh. Math. 71 (1967), 385-392.

3. H. E. Gollwitzer, Nonoscillation theorems for nonlinear second order equations (to appear)

4. Philip Hartman, Ordinary differential equations, John Wiley and Sons, Inc., New York, 1964.

5. J. W. Heidel, A nonoscillation theorem for a nonlinear second order differential equation, Proc. Amer. Math. Soc. 22 (1969), 2, 485-488.

6. I. T. Kiguradze, The problem of oscillation of solutions of nonlinear differential equations (Russian), Differencial'nye Uravenija 1 (1965), 995-1006 (translated as Differential Equations) 1 (1965), 773-782.

7. Remarks on the oscillation of solutions of the equation $u^{\prime \prime}+a(t)|u|^{n} \operatorname{sgn} u=$ 0 (Russian), Časopis Psět. Mat. 92 (1967), 343-350.

Received March 18, 1969.

The University of Tennessee 



\title{
PACIFIC JOURNAL OF MATHEMATICS
}

\author{
EDITORS
}

H. SAMELSON

Stanford University

Stanford, California 94305

J. DugunduI

Department of Mathematics

University of Southern California

Los Angeles, California 90007

RICHARD PIERCE

University of Washington

BASIL GORDON*

University of California

Seattle, Washington 98105

Los Angeles, California 90024

\section{ASSOCIATE EDITORS}

E. F. BeCKenbaCh

B. H. NeumanN

F. WOLF

K. YosHIDA

\section{SUPPORTING INSTITUTIONS}

\author{
UNIVERSITY OF BRITISH COLUMBIA \\ CALIFORNIA INSTITUTE OF TECHNOLOGY \\ UNIVERSITY OF CALIFORNIA \\ MONTANA STATE UNIVERSITY \\ UNIVERSITY OF NEVADA \\ NEW MEXICO STATE UNIVERSITY \\ OREGON STATE UNIVERSITY \\ UNIVERSITY OF OREGON \\ OSAKA UNIVERSITY \\ UNIVERSITY OF SOUTHERN CALIFORNIA
}

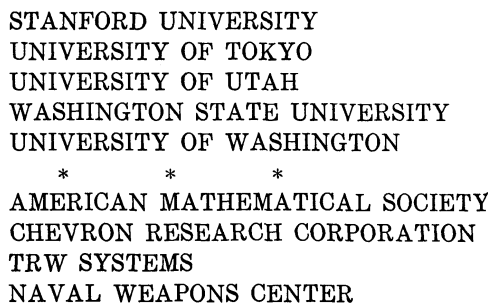

The Supporting Institutions listed above contribute to the cost of publication of this Journal, but they are not owners or publishers and have no responsibility for its content or policies.

Mathematical papers intended for publication in the Pacific Journal of Mathematics should be in typed form or offset-reproduced, double spaced with large margins. Underline Greek letters in red, German in green, and script in blue. The first paragraph or two must be capable of being used separately as a synopsis of the entire paper. It should not contain references to the bibliography. Manuscripts, in duplicate if possible, may be sent to any one of the four editors. Please classify according to the scheme of Math. Rev. 36, 1539-1546. All other communications to the editors should be addressed to the managing editor, Richard Arens, University of California, Los Angeles, California, 90024.

50 reprints are provided free for each article; additional copies may be obtained at cost in multiples of 50 .

The Pacific Journal of Mathematics is published monthly. Effective with Volume 16 the price per volume (3 numbers) is $\$ 8.00$; single issues, $\$ 3.00$. Special price for current issues to individual faculty members of supporting institutions and to individual members of the American Mathematical Society: $\$ 4.00$ per volume; single issues $\$ 1.50$. Back numbers are available.

Subscriptions, orders for back numbers, and changes of address should be sent to Pacific Journal of Mathematics, 103 Highland Boulevard, Berkeley, California, 94708.

PUBLISHED BY PACIFIC JOURNAL OF MATHEMATICS, A NON-PROFIT CORPORATION

Printed at Kokusai Bunken Insatsusha (International Academic Printing Co., Ltd.), 7-17, Fujimi 2-chome, Chiyoda-ku, Tokyo, Japan.

* Acting Managing Editor. 


\section{Pacific Journal of Mathematics}

\section{Vol. 32, No. 3 \\ March, 1970}

Shair Ahmad, Dynamical systems of characteristic $0^{+} \ldots \ldots \ldots \ldots \ldots$

Charles A. Akemann and Bernard Russo, Geometry of the unit sphere of a $C^{*}$-algebra and its dual............................ 575

Philip Bacon, The compactness of countably compact spaces ......... 587

Richard Blaine Barrar and Henry Loeb, On the continuity of the nonlinear Tschebyscheff operator ............................ 593

L. Carlitz, Factorization of a special polynomial over a finite field ....... 603

Joe Ebeling Cude, Compact integral domains .................... 615

Frank Rimi DeMeyer, On automorphisms of separable algebras. II . . . . . 621

James B. Derr, Generalized Sylow tower groups .................. 633

Raouf Doss, Some inclusions in multipliers ................... 643

Mary Rodriguez Embry, The numerical range of an operator........... 647

John Froese, Domain-perturbed problems for ordinary linear differential

operators..................................... 651

Zdeněk Frolík, Absolute Borel and Souslin sets ..................... 663

Ronald Owen Fulp, Tensor and torsion products of semigroups .......... 685

George Grätzer and J. Płonka, On the number of polynomials of an

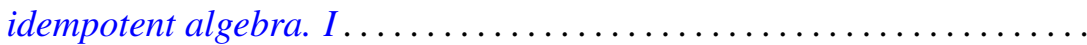

Newcomb Greenleaf and Walter Read, Positive holomorphic differentials on

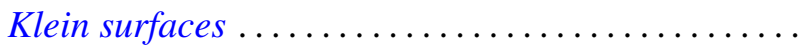

John Willard Heidel, Uniqueness, continuation, and nonoscillation for a second order nonlinear differential equation ................. 715

Leon A. Henkin, Extending Boolean operations................... 723

R. Hirshon, On hopfian groups .......................... 753

Melvin Hochster, Totally integrally closed rings and extremal spaces ..... 767

R. Mohanty and B. K. Ray, On the convergence of a trigonometric integral ..................................

Michael Rich, On a class of nodal algebras .................... 787

Emile B. Roth, Conjugate space representations of Banach spaces ........ 793

Rolf Schneider, On the projections of a convex polytope .............. 799

Bertram Manuel Schreiber, On the coset ring and strong Ditkin sets ...... 805

Edgar Lee Stout, Some remarks on varieties in polydiscs and bounded

holomorphic functions .........................

James Edward Ward, Two-groups and Jordan algebras . 